\title{
Disease-related disability burden: a comparison of seven chronic conditions in middle-aged and older adults
}

\author{
Chieh-Ying Chou ${ }^{1,2}$, Ching-Ju Chiu ${ }^{1 *}$ (D), Chia-Ming Chang ${ }^{1,3,4}$, Chih-Hsing Wu ${ }^{1,2,5}$, Feng-Hwa Lu ${ }^{1,2,5}$,
} Jin-Shang $\mathrm{Wu}^{2,5}$ and Yi-Ching Yang ${ }^{2,5}$

\begin{abstract}
Background: Although previous studies have explored the effect of chronic conditions on physical disability, little is known about the levels and rates of change in physical disability after a chronic condition diagnosis in middle-aged and older adults in the Asian population. The aim of this study is to ascertain the average levels and rates of change in the development of disability after disease diagnosis, as well as to determine the influences of sociodemographic and health-related correlates in the development of disability.

Methods: This is a retrospective cohort study analyzing data of nationally representative participants aged 50 and over with a chronic condition or having developed one during follow-ups based on data from the 1996-2011 Taiwan Longitudinal Study on Aging (TLSA) $(n=5131)$. Seven chronic conditions were examined. Covariates included age at initial diagnosis, gender, education level, number of comorbidities, and depression status. Physical disability was measured by combining self-reported $A D L, I A D L$, and strength and mobility activities with 17 total possible points, further analyzed with multilevel modeling.

Results: The results showed that (1) physical disability was highest for stroke, followed by cancer and diabetes at the time of the initial disease diagnosis. (2) The linear rate of change was highest for stroke, followed by lung disease and heart disease, indicating that these diseases led to higher steady increases in physical disability after the disease diagnosis. (3) The quadratic rate of change was highest in diabetes, followed by cancer and hypertension, indicating that these diseases had led to higher increments of physical disability in later stage disease. After controlling for sociodemographic and comorbidity, depression status accounted for $39.9-73.6 \%$ and $37.9-100 \%$ of the variances in the physical disability intercept and change over time, respectively.

Conclusions: Despite the fact that a comparison across conditions was not statistically tested, an accelerated increase in physical disabilities was found as chronic conditions progressed. While stroke and cancer lead to disability immediately, conditions such as diabetes, cancer, and hypertension give rise to higher increments of physical disability in later stage disease. Mitigating depressive symptoms may be beneficial in terms of preventing disability development in this population.
\end{abstract}

Keywords: Physical disability, Trajectory, Chronic condition, Middle-aged and older Taiwanese

\footnotetext{
* Correspondence: cjchiu@mail.ncku.edu.tw

${ }^{1}$ Institute of Gerontology, College of Medicine, National Cheng Kung

University, No. 1, University Road, 70101 Tainan, Taiwan

Full list of author information is available at the end of the article
}

(c) The Author(s). 2021 Open Access This article is licensed under a Creative Commons Attribution 4.0 International License, which permits use, sharing, adaptation, distribution and reproduction in any medium or format, as long as you give appropriate credit to the original author(s) and the source, provide a link to the Creative Commons licence, and indicate if changes were made. The images or other third party material in this article are included in the article's Creative Commons licence, unless indicated otherwise in a credit line to the material. If material is not included in the article's Creative Commons licence and your intended use is not permitted by statutory regulation or exceeds the permitted use, you will need to obtain permission directly from the copyright holder. To view a copy of this licence, visit http://creativecommons.org/licenses/by/4.0/. The Creative Commons Public Domain Dedication waiver (http://creativecommons.org/publicdomain/zero/1.0/) applies to the data made available in this article, unless otherwise stated in a credit line to the data. 


\section{Background}

Over recent decades, the global population of elderly people increased from $5 \%$ in 1950 to a projected $16 \%$ by 2050 [1] and is aging rapidly, especially in Asian countries, including Taiwan. The ratio of the population aged $\geq 65$ years in Taiwan reached 14\% (cut-off point for an "aged" society) in 2018, and estimates are that the ratio will rise to $20 \%$ (cut-off point for a "super-aged" society) by 2026 . In 2065 , older people could account for $41.2 \%$ of the entire Taiwanese population [2]. The increase in the number of older people raises concern about a growing strain on healthcare systems.

Chronic disease is a common issue in the elderly population and is the primary health problem in this population, leading to physical disability and even death. In Taiwan, the prevalence rate of at least one chronic disease among elderly people aged over 65 years old is $81.1 \%$, and the prevalence of chronic diseases in elderly people ranks in the following order: hypertension (54.5\%), osteoporosis (32.9\%), diabetes mellitus (24.7\%), heart disease (21.5\%), and dyslipidemia (19.6\%) [3]. Previous studies have shown that disability is one complication of chronic diseases [4-6] and also accounts for the vast majority of healthcare expenditures [7]. Due to the rapid growth of the elderly population and lifespan elongation, it is worth investigating which chronic diseases lead to greater levels of disability in the elderly population and the associated factors that lead to physical disabilities.

Physical disabilities seriously threaten the independence and quality of life of the elderly population and are generally evaluated according to the ability of individuals to perform activities of daily living (ADLs) [8] and instrumental activities of daily living (IADLs) [9]. Limitations on activities requiring strength and mobility are also regarded as an early sign of frailty and a predictor of later functional disability [10]. Previous studies discussing disability have mainly focused on the measurement of ADLs [11, 12]. Nevertheless, broader evaluations that include difficulties in the IADLs and in strength and mobility can help address the recent trend toward promoting the health of the elderly population [13, 14]. This composite measure makes it possible to assess a broader range of physical disabilities, from preclinical disabilities to later personal care disabilities.

Recent cross-sectional studies have shown that chronic diseases such as arthritis [12, 15], heart disease [12], lung disease [12], hypertension [16, 17], diabetes mellitus [18] and stroke [12] are associated with physical disability in the elderly population. In addition, several longitudinal studies have demonstrated that chronic conditions increase the risk of disability, such as stroke [19], acute myocardial infarction [19], diabetes mellitus [14, 20], chronic obstructive pulmonary disease [21] and arthritis
[11]. However, the aforementioned studies mainly explored disability in terms of single diseases with short follow-up intervals and fewer repeated follow-up points. In addition, only one study conducted in the U.S. explored an age-related physical functioning trajectory for several common chronic conditions [13]. However, prevalent and incident diseases could not be differentiated in that study. Also, this study was conducted in a western country, and different country and ethnicity may also lead to different disability trajectories. To the best of our knowledge, there is no study available in eastern countries discussing the trajectory of physical disability after a disease diagnosis among various chronic conditions. So as to fill the current research gaps, the aim of this study is to (1) ascertain the average levels and rates of change in the development of disability after disease diagnosis and (2) determine the influences of sociodemographic and health-related correlates in the development of disability.

\section{Methods \\ Participants}

In this study, datasets from the Taiwan Longitudinal Study on Aging (TLSA), an ongoing nationally representative panel survey that collects information on a number of variables related to physical and mental health, living and social arrangement, and retirement planning in middle-aged and older Taiwanese individuals, were used. The initial cohort in 1989 included 4049 participants aged $\geq 60$ years old and re-interviewed every 3-4 years. Later in 1996, another 2462 participants aged 50 to 66 years was supplemented in the original cohort. As a result, the 1996 TLSA sample represented the entire Taiwanese population aged 50 and over living in an institution or in the community $(n=5131)$. A detailed description of the enrollment in the TLSA have been described previously [20]. The Ethical Committee for Human Research at National Cheng Kung University Hospital approved this study (B-ER-104-077). The analytic sample included the data from the 1996, 1999, 2003, 2007, and 2011 interview waves. Self-reported chronic conditions in 1996 and newly diagnosed chronic conditions during follow-ups were included in the final analysis, yielding a sample of 1435 participants with hypertension, 1193 with arthritis, 915 with heart disease, 614 with lung disease, 570 with diabetes mellitus, 277 with stroke, and 192 with cancer.

\section{Chronic conditions}

The chronic conditions' status was defined by selfreported answers to the dichotomous question "Have you been diagnosed with hypertension, heart disease, stroke, diabetes mellitus, cancer, lung disease, or arthritis by a physician?" Self-reported chronic conditions in 
1996 and newly diagnosed chronic conditions during follow-ups until 2011 were collected for each chronic condition.

\section{Duration after the diagnosis of a chronic condition}

The duration after the diagnosis of a chronic condition was recorded for prevalent cases in 1996 and incident cases between 1999 and 2011. For participants who selfreported chronic conditions in 1996, the duration of disease equaled an additional 3 years in 1999, an additional 7 years in 2003, an additional 11 years in 2007, and an additional 15 years in 2011. As for the self-reported newly diagnosed participants between 1999 and 2011, the duration after the diagnosis of a chronic condition was assumed to be 2 years (rounding up 1.5 years in 1999 to the nearest integer) in the reporting wave, and additional 6, 10, 14 years in the following wave, respectively).

\section{Physical disability scores}

Participants in the TLSA cohort were assessed at each wave whether they had any limitation to carry out each of a number of different tasks, including six ADLs (eating, dressing, bathing, toileting, walking across a room, and getting in/out of bed, independently) [8], four IADLs (shopping for personal items, making a phone call, doing light housework, and riding a bus or train) [9], and seven strength and mobility activities (reaching above the head, stooping/ kneeling/or crouching, standing for $15 \mathrm{~min}$, walking $200-300 \mathrm{~m}$, running a short distance $(20-30 \mathrm{~m})$, climbing one or two flights of stairs, and lifting or carrying weights over 10 pounds like a heavy bag of groceries) [22]. Physical disability scores were the sum of the 17 dichotomous scores for the $\mathrm{ADL}$, IADL, and strength and mobility activities, where 0 means no difficulties and 1 means some difficulties, and higher scores indicate more severe limitations (range 0-17).

\section{Other variables}

Sociodemographic and health-related covariates that may interfere with physical disability conditions were measured at each wave. Sociodemographic variables included age at initial diagnosis (centered to 70 years old), gender, and education level. Education level was divided into two groups, based on having received formal education and being literate or illiterate. Health-related variables included a number of comorbidities and depression status, and they were modeled as time-varying covariates. The number of comorbidities was defined from a count of selected chronic conditions that the participants self-reported they had been diagnosed with (range 0-6). The 10-item short form of the Centers for Epidemiological Studies-Depression (CES-D) scale [23] scores were measured at each wave (range 0-30). Depression status was divided into two groups according to a CES-D score $\geqq 10$ or below for the purpose of identifying level of depression [24].

\section{Statistical analyses}

The data were analyzed using SAS software version 9.4 (SAS Institute, Inc., Cary, NC). Pearson's $\chi^{2}$ tests and $t$ tests were used to compare the differences between the characteristics of participants who suffered from chronic conditions in 1996 and those who did not. $p<0.05$ was considered to be statistically significant. Because multilevel modeling (MLM) [25] has the capacity to handle the irregular interview interval and control for timevarying covariates, it was used to examine the physical disability trajectories after disease diagnosis and computed different models for each chronic condition. The MLM equation models are shown as follows:

Level-1 model:

$$
\begin{aligned}
Y_{i j}= & \left.\pi_{0 j}+\pi_{1 j} \text { (years from diagnosis }\right)_{i j} \\
& \left.+\pi_{2 j} \text { (years from diagnosis }\right)^{2}{ }_{i j}+r_{i j}
\end{aligned}
$$

where

$$
r_{i j} \sim N\left(0, \sigma^{2}\right)
$$

Level-2 model:

$$
\begin{gathered}
\pi_{0 j}=\beta_{00}+\beta_{01} \operatorname{COVAR}_{j}+u_{0 j}, \\
\pi_{1 j}=\beta_{10}+\beta_{11} \operatorname{COVAR}_{j}+u_{1 j}, \\
\pi_{2 j}=\beta_{20}+u_{2 j},
\end{gathered}
$$

where

$$
\left(\begin{array}{l}
u_{o j} \\
u_{1 j} \\
u_{2 j}
\end{array}\right) \sim N\left[\left(\begin{array}{l}
0 \\
0 \\
0
\end{array}\right),\left(\begin{array}{lll}
\tau_{00} & \tau_{01} & \tau_{02} \\
\tau_{10} & \tau_{11} & \tau_{12} \\
\tau_{20} & \tau_{21} & \tau_{22}
\end{array}\right)\right] .
$$

Initially, we use a model with the intercept, linear, and quadratic growth curve models of physical disability after a chronic condition diagnosis. Then, four models were built within each health outcome. Model 0 represented the independent effect on the levels and rates of change in physical disability among different chronic conditions. The intercept and slope coefficient represented the average level at disease diagnosis and linear rate of change in physical disability after disease diagnosis, respectively. The quadratic term coefficient described an accelerated increase or decrease per year. Model 1 added sociodemographic covariates, including age at initial diagnosis, gender, and education level, with a reference group of males and participants who had received a formal education or were literate. Model 2 added the number of comorbidities treated as time-varying 
covariates to control for the effect of morbidity. Model 3 added time-varying depression status based on Model 2.

\section{Results}

The baseline characteristics of the participants with and without common chronic conditions in 1996 are shown in Table 1. The number and percentage for each chronic condition in 1996 were 1344 (26.2\%) with hypertension, $743(14.5 \%)$ with heart disease, $233(4.5 \%)$ with stroke, 559 (10.9\%) with diabetes, 68 (1.3\%) with cancer, 497 (9.7\%) with lung disease, and 924 (18\%) with arthritis, respectively. The participants were older in stroke, heart disease, and lung disease. Participants were predominantly female in hypertension, diabetes, heart disease, and arthritis, whereas more males had been diagnosed with stroke and lung disease. Participants with diabetes, heart disease, and arthritis revealed lower education level. The comorbidity levels were highest for stroke, followed by heart disease and cancer. The highest physical disability scores were 9.44 $(\mathrm{SD}=6.56)$ for stroke, followed by cancer $($ mean $=4.72, \mathrm{SD}=5.50)$, heart disease $($ mean $=3.77$, $\mathrm{SD}=4.45)$, lung disease (mean $=3.70, \mathrm{SD}=4.68)$, diabetes $($ mean $=3.69, \mathrm{SD}=4.82)$, arthritis $($ mean $=3.50$, $\mathrm{SD}=4.14)$, and hypertension ( mean $=3.28, \mathrm{SD}=4.55$ ).

Table 2 shows the changes in mean physical disability scores related to years after diagnosis. The results revealed that there was an increasing growth pattern in physical disability after disease diagnosis, which means that it was appropriate to use multilevel modeling method to measure physical disability.

Table 3 shows the physical disability trajectories for participants with different newly diagnosed chronic conditions over time. In Model 0, the estimated intercept, linear, and quadratic changes in physical disability without controlling for any covariates were determined, for which the mean growth trajectories of physical disability are shown in Fig. 1. We found that (1) the physical disability was highest for stroke $\left(\beta_{\text {stroke }}=8.104,95 \% \mathrm{CI}=\right.$ 7.203-9.004), followed by cancer $\left(\beta_{\text {cancer }}=3.693,95 \%\right.$ $\mathrm{CI}=2.880-4.506)$ and diabetes $\left(\beta_{\text {diabetes }}=2.887,95 \%\right.$ $\mathrm{CI}=2.442-3.332)$ at initial disease diagnosis. (2) The linear rate of change in physical disability after disease diagnosis was highest for stroke $\left(\beta_{\text {stroke"time }}=0.203,95 \%\right.$ $\mathrm{CI}=0.041-0.364)$, followed by lung disease ( $\beta_{\text {lung disease"- }}$ time $=0.200,95 \% \mathrm{CI}=0.144-0.257)$ and heart disease ( $\beta_{\text {heart disease }}$ time $\left.=0.155,95 \% \mathrm{CI}=0.102-0.207\right)$, indicating that these diseases led to a higher steady increase in physical disability after disease diagnosis. (3) The quadratic rate of change in physical disability after disease diagnosis was highest for diabetes $\left(\beta_{\text {diabetes"time }}{ }^{2}=0.014\right.$, $95 \% \mathrm{CI}=0.010-0.017)$, followed by cancer $\left(\beta_{\text {cancer"time }^{2}}=\right.$ $0.013,95 \% \mathrm{CI}=0.007-0.020)$ and hypertension ( $\beta_{\text {hyper- }}$ tension $^{*}{ }^{2}=0.010, \quad 95 \% \mathrm{CI}=0.009-0.012$ ), indicating that these diseases exhibited higher increments of physical disability at later stages of disease. Furthermore, we also determined the estimated changes in physical disability at 5-year intervals after diagnosis of each chronic condition, for which the results are presented in Table 4.

Model 1 added sociodemographic variables, including age at diagnosis, gender, and education level to determine the impact of these variables on physical disability. These models all significantly improved the model fit from Model 0, indicating that the aforementioned variables were significant predictors of interindividual variations in the physical disability trajectories among the chronic conditions under consideration, accounting for $20.3-35.2 \%$ of the variances changes in the mean physical disability intercept and $17.5-41.4 \%$ of the variances changes in physical disability over time for different chronic conditions, respectively, for which the detailed results are shown in Table 5. After controlling for sociodemographic variables, participants with stroke $\left(\beta_{\text {stroke }}=\right.$ 5.104, 95\% CI $=4.040-6.169)$, diabetes $\left(\beta_{\text {diabetes }}=2.209\right.$, $95 \% \mathrm{CI}=1.676-2.742)$, and cancer $\left(\beta_{\text {cancer }}=2.053,95 \%\right.$ $\mathrm{CI}=1.079-3.027)$ still had higher physical disability scores at the initial disease diagnosis. This result indicated that these diseases are independent of sociodemographic characteristics. For participants with lung disease, the significant quadratic rate of change disappeared after controlling for sociodemographic variables, suggesting that sociodemographic covariates play a crucial role in lung disease.

Model 2 represented the influence of each chronic condition on physical disability while controlling for sociodemographic variables and time-varying comorbidities. The significance of linear and quadratic rates of change in physical disability in chronic conditions remained unchanged from Model 1 to Model 2 and accounted for $0-12.7 \%$ of the changes in the variances in the mean physical disability intercept and -8.8 to $6.2 \%$ of the changes in the variances in the physical disability over time for different chronic conditions. The negative value obtained for the changes in variance between the models for stroke and cancer indicated that comorbidity plays no role in physical disability in the case of these two diseases. After controlling for the above referenced covariates, participants with stroke $\left(\beta_{\text {stroke }}=4.509,95 \% \mathrm{CI}=3.293-5.724\right)$, cancer $\left(\beta_{\text {cancer }}=\right.$ $1.156,95 \% \mathrm{CI}=0.172-3.027)$, and diabetes $\left(\beta_{\text {diabetes }}=\right.$ $1.080,95 \% \mathrm{CI}=0.517-1.643)$ retained higher physical disability scores at the initial disease diagnosis.

Model 3 represented the influence of each chronic condition on physical disability after controlling for sociodemographic variables, time-varying comorbidities, and depression status. The changes in the variances from Model 2 to Model 3 accounted for $39.9-73.6 \%$ of the mean physical disability intercept and $37.9-100 \%$ of 


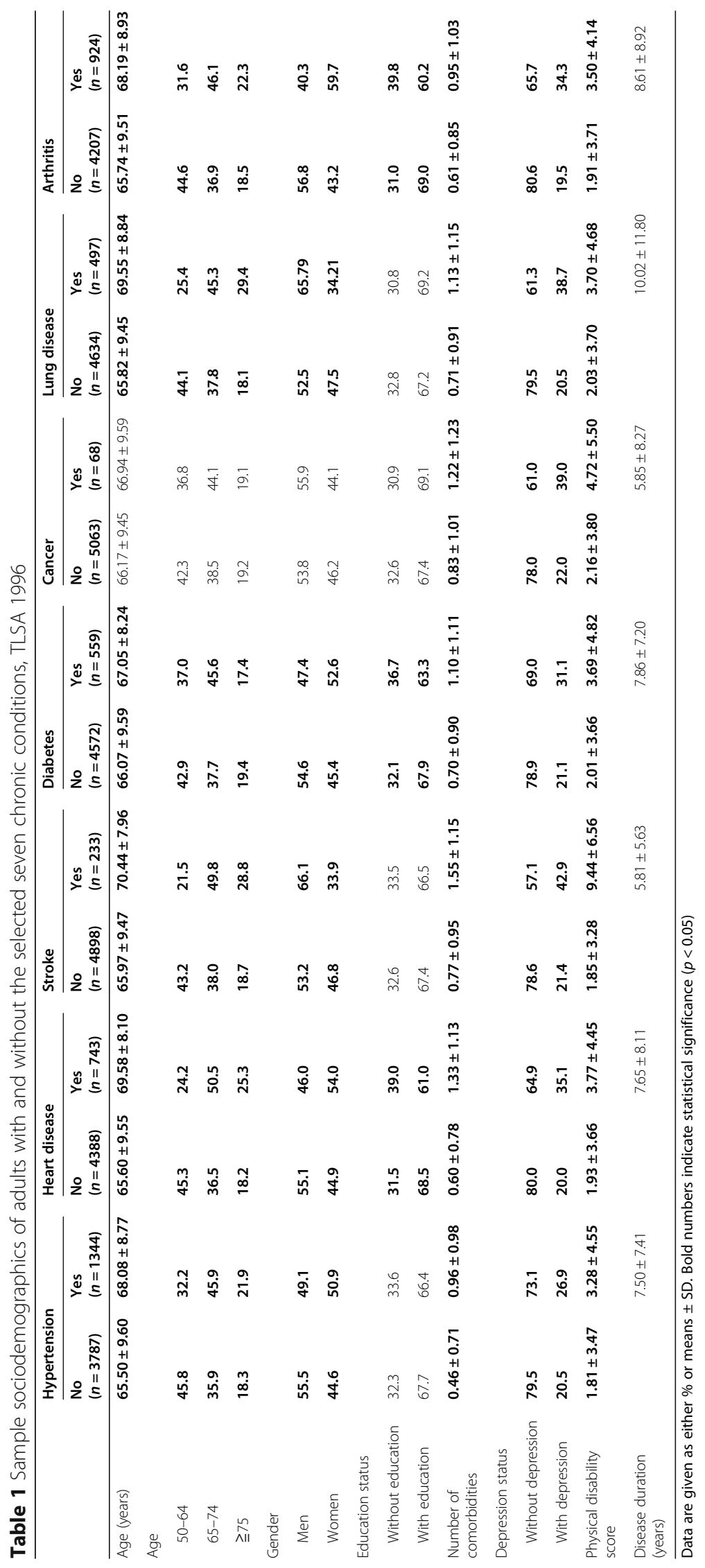


Table 2 Raw mean scores and standard deviations of physical disability development of participants with different chronic conditions

\begin{tabular}{llllllll}
\hline & Hypertension & Heart disease & Stroke & Diabetes & Cancer & Lung disease & Arthritis \\
\hline Before diagnosis & $1.86 \pm 3.08$ & $2.18 \pm 3.29$ & $2.87 \pm 3.81$ & $2.42 \pm 3.65$ & $2.03 \pm 3.19$ & $2.69 \pm 3.90$ & $2.10 \pm 3.25$ \\
2 years after diagnosis & $3.89 \pm 4.98$ & $4.66 \pm 5.06$ & $9.77 \pm 6.31$ & $4.83 \pm 5.38$ & $5.43 \pm 5.57$ & $5.08 \pm 5.50$ & $4.27 \pm 4.67$ \\
6 years after diagnosis & $4.28 \pm 5.09$ & $4.93 \pm 5.19$ & $9.22 \pm 6.27$ & $4.91 \pm 5.55$ & $4.28 \pm 4.76$ & $5.12 \pm 5.54$ & $4.64 \pm 4.90$ \\
10 years after diagnosis & $4.76 \pm 5.47$ & $5.52 \pm 5.38$ & $9.46 \pm 6.42$ & $5.75 \pm 5.80$ & $4.89 \pm 5.28$ & $5.34 \pm 5.57$ & $5.32 \pm 5.26$ \\
14 years after diagnosis & $5.52 \pm 5.81$ & $6.13 \pm 5.66$ & $8.86 \pm 6.23$ & $6.20 \pm 6.30$ & $5.63 \pm 5.48$ & $6.02 \pm 5.84$ & $5.49 \pm 5.44$ \\
\hline
\end{tabular}

Table 3 Levels and rates of change in the physical disability trajectory after diagnosis for each chronic condition

\begin{tabular}{|c|c|c|c|c|c|c|c|}
\hline & & \multicolumn{3}{|l|}{ Fixed effect } & \multicolumn{3}{|c|}{ Goodness of fit } \\
\hline & & Intercept & Linear change & Quadratic change & $-2 L L$ & Parameters & LR test ${ }^{\Delta} \mathrm{X}^{2}(\Delta \mathrm{df})$ \\
\hline \multirow[t]{4}{*}{ Hypertension } & Model 0 & $1.858(1.615-2.101)$ & $0.087(0.046-0.129)$ & $0.010(0.009-0.012)$ & $25,401.7$ & 7 & \\
\hline & Model 1 & $1.028(0.735-1.320)$ & $0.174(0.132-0.216)$ & $0.007(0.005-0.008)$ & $24,851.0$ & 12 & $550.7(5)^{* * *}$ \\
\hline & Model 2 & $0.441(0.150-0.731)$ & $0.154(0.113-0.196)$ & $0.006(0.005-0.008)$ & $24,591.9$ & 13 & $259.1(1)^{* * *}$ \\
\hline & Model 3 & $0.271(0.030-0.512)$ & $0.120(0.085-0.156)$ & $0.004(0.003-0.006)$ & $21,169.2$ & 15 & $3422.7(2)^{* * *}$ \\
\hline \multirow[t]{4}{*}{ Heart disease } & Model 0 & $2.538(2.223-2.853)$ & $0.155(0.102-0.207)$ & $0.008(0.006-0.010)$ & $16,068.7$ & 7 & \\
\hline & Model 1 & $1.358(0.959-1.756)$ & $0.235(0.183-0.288)$ & $0.004(0.002-0.007)$ & $15,684.4$ & 12 & $384.3(5)^{* * *}$ \\
\hline & Model 2 & $0.425(0.009-0.841)$ & $0.222(0.170-0.274)$ & $0.004(0.002-0.006)$ & $15,563.0$ & 13 & $121.4(1)^{* * *}$ \\
\hline & Model 3 & $0.558(0.208-0.908)$ & $0.161(0.117-0.205)$ & $0.003(0.001-0.004)$ & $13,317.3$ & 15 & $2245.7(2)^{* * *}$ \\
\hline \multirow[t]{4}{*}{ Stroke } & Model 0 & $8.104(7.203-9.004)$ & $0.203(0.041-0.364)$ & $0.005(-0.004-0.014)$ & 3632.9 & 7 & \\
\hline & Model 1 & $5.104(4.040-6.169)$ & $0.288(0.129-0.447)$ & $0.001(-0.007-0.010)$ & 3510.6 & 12 & $122.3(5)^{* * *}$ \\
\hline & Model 2 & $4.509(3.293-5.724)$ & $0.289(0.130-0.449)$ & $0.001(-0.008-0.009)$ & 3506.7 & 13 & $3.9(1)^{*}$ \\
\hline & Model 3 & $3.018(1.861-4.175)$ & $0.215(0.054-0.376)$ & $0.002(-0.007-0.010)$ & 2495.0 & 15 & $1011.7(2)^{* * *}$ \\
\hline \multirow[t]{4}{*}{ Diabetes } & Model 0 & $2.887(2.442-3.332)$ & $0.080(-0.001-0.161)$ & $0.014(0.010-0.017)$ & 9469.6 & 7 & \\
\hline & Model 1 & $2.209(1.676-2.742)$ & $0.173(0.091-0.255)$ & $0.009(0.005-0.012)$ & 9207.5 & 12 & $262.1(5)^{* * *}$ \\
\hline & Model 2 & $1.080(0.517-1.643)$ & $0.166(0.086-0.247)$ & $0.008(0.004-0.011)$ & 9102.6 & 13 & $104.9(1)^{* * *}$ \\
\hline & Model 3 & $0.805(0.331-1.278)$ & $0.105(0.037-0.172)$ & $0.006(0.003-0.009)$ & 7680.5 & 15 & $1422.1(2)^{* * *}$ \\
\hline \multirow[t]{4}{*}{ Cancer } & Model 0 & $3.693(2.880-4.506)$ & $0.013(-0.137-0.163)$ & $0.013(0.007-0.020)$ & 2554.0 & 7 & \\
\hline & Model 1 & $2.053(1.079-3.027)$ & $0.133(-0.015-0.282)$ & $0.009(0.002-0.016)$ & 2467.9 & 12 & $86.1(5)^{* * *}$ \\
\hline & Model 2 & $1.156(0.172-2.141)$ & $0.088(-0.063-0.238)$ & $0.009(0.003-0.016)$ & 2442.1 & 13 & $25.8(1)^{* * *}$ \\
\hline & Model 3 & $0.542(-0.184-1.268)$ & $0.079(-0.041-0.198)$ & $0.007(0.001-0.012)$ & 2011.6 & 15 & $430.5(2)^{* * *}$ \\
\hline \multirow[t]{4}{*}{ Lung disease } & Model 0 & $2.526(2.100-2.953)$ & $0.200(0.144-0.257)$ & $0.003(0.002-0.005)$ & $10,865.3$ & 7 & \\
\hline & Model 1 & $1.336(0.863-1.810)$ & $0.305(0.251-0.360)$ & $-0.0004(-0.002-0.001)$ & $10,486.0$ & 12 & $379.3(5)^{* * *}$ \\
\hline & Model 2 & $0.681(0.192-1.170)$ & $0.291(0.236-0.345)$ & $-0.001(-0.003-0.001)$ & $10,427.1$ & 13 & $58.9(1)^{* * *}$ \\
\hline & Model 3 & $0.366(-0.017-0.750)$ & $0.213(0.175-0.250)$ & $-0.001(-0.002$ to -0.0003$)$ & 8713.5 & 15 & $1713.6(2)^{* * *}$ \\
\hline \multirow[t]{4}{*}{ Arthritis } & Model 0 & $2.205(1.942-2.468)$ & $0.119(0.077-0.161)$ & $0.007(0.005-0.008)$ & $22,100.0$ & 7 & \\
\hline & Model 1 & $1.466(1.132-1.800)$ & $0.226(0.184-0.268)$ & $0.003(0.002-0.005)$ & $21,496.9$ & 12 & $603.1(5)^{* * *}$ \\
\hline & Model 2 & $0.833(0.492-1.174)$ & $0.204(0.162-0.245)$ & $0.003(0.001-0.004)$ & $21,353.7$ & 13 & $143.2(1)^{* * *}$ \\
\hline & Model 3 & $0.613(0.322-0.903)$ & $0.183(0.146-0.219)$ & $0.001(-0.001-0.002)$ & $18,683.7$ & 15 & $2670.0(2)^{* * *}$ \\
\hline
\end{tabular}

Scores of physical disability are the total of limitations in ADL, IADL, and mobility (range 0-17)

Bold numbers and *indicate statistical significance $(p<0.05)$, **indicate statistical significance $(p<0.001)$

Model 0: Duration after diagnosis and (duration after diagnosis) ${ }^{2}$

Model 1: Model $0+$ age at diagnosis (centered to 70 years old), gender, education level

Model 2: Model $1+$ number of comorbidities over time

Model 3: Model $2+$ depression status over time 


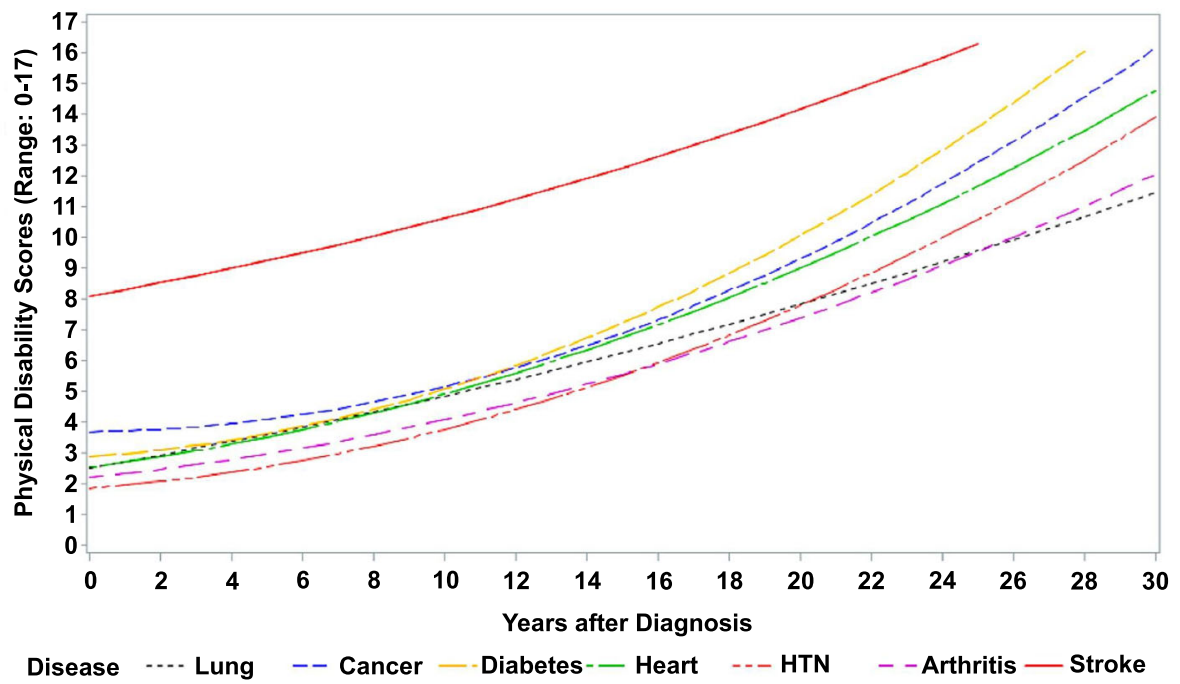

Fig. 1 Physical disability trajectories after diagnosis for each chronic condition in adults over 50 years of age (TLSA 1996-2011)

physical disability over time for different chronic conditions, suggesting that depression status was a robust factor in all chronic conditions. After controlling for the covariates discussed earlier, participants with stroke $\left(\beta_{\text {stroke }}=3.018,95 \% \mathrm{CI}=1.861-4.175\right)$, diabetes $\left(\beta_{\text {dia- }}\right.$ betes $=0.805,95 \% \mathrm{CI}=0.331-1.278)$, and arthritis $\left(\beta_{\text {arthri- }}\right.$ tis $=0.613, \quad 95 \% \quad C I=0.322-0.903) \quad$ retained higher physical disability scores at the initial disease diagnosis.

\section{Discussion}

To the best of our knowledge, this is the first long-term, population-based nationally representative study to compare the physical disability trajectories after common chronic conditions diagnosis in middle-aged and older adults in the Asian population. Among the seven chronic conditions under consideration, the results showed that (1) at the initial disease diagnosis, physical disability was highest for stroke, followed by cancer and diabetes. (2) The linear rate of change was highest for stroke, followed by lung disease and heart disease. (3) The quadratic rate of change was highest in diabetes, followed by cancer and hypertension, indicating that these diseases showed higher increments of physical disability in later stage disease.
Prior literature comparing multiple chronic conditions has shown that stroke is the most disabling disease [13, 26,27 , which is consistent with our findings. However, an examination of disability in other diseases led to inconsistent results. Previous studies have shown that stroke, treated diabetes, chronic airway obstruction, coronary heart disease, and treated hypertension are all significantly associated with onset of disability [26]. Another study showed newly occurring conditions such as stroke, followed by cancer, heart attack, and diabetes followed up for 6 years led to greater relative risks for developing incident disability in ADL [27]. In addition, one cohort study found that stroke, followed by pulmonary diseases and arthritis, was associated with greater physical functioning difficulties compared with heart disease, cancer, and diabetes [13]. The inconsistency of disabilities in disease rankings among the aforementioned studies may be related to different disability outcome measurements, different study designs, and different countries and ethnicities. The current work provided evidence of average levels and rates of change in physical disability after chronic condition diagnoses in an Asian population.

Previous studies have shown that sociodemographic variables are associated with disabilities, including age,

Table 4 Disease-related disability burden based on fixed effect coefficients for Model 0

\begin{tabular}{llllllll}
\hline & Hypertension & Heart disease & Stroke & Diabetes & Cancer & Lung disease & Arthritis \\
\hline Initial diagnosis & 1.858 & 2.538 & 8.104 & 2.887 & 3.693 & 2.526 & 2.205 \\
5 years & 2.543 & 3.513 & 9.244 & 3.637 & 4.083 & 3.601 & 2.975 \\
10 years & 3.728 & 4.888 & 10.634 & 5.087 & 5.123 & 4.826 & 4.095 \\
15 years & 5.413 & 6.663 & 12.274 & 7.237 & 6.813 & 6.201 & 5.565 \\
20 years & 7.598 & 8.838 & 14.164 & 10.087 & 9.153 & 7.726 & 7.385 \\
25 years & 11.283 & 12.213 & 16.804 & 15.037 & 13.443 & 9.701 & 10.255 \\
\hline
\end{tabular}


Table 5 Comparison of random effects of the different chronic conditions on the nested models

\begin{tabular}{|c|c|c|c|c|c|}
\hline & & Variance of intercept $(1,1)$ & $\begin{array}{l}\text { Percentage of variance } \\
\text { change from previous models }\end{array}$ & Variance of slope $(1,1)$ & $\begin{array}{l}\text { Percentage of variance } \\
\text { change from previous models }\end{array}$ \\
\hline \multirow[t]{4}{*}{ Hypertension } & Model 0 & 8.516 & & 0.105 & \\
\hline & Model 1 & 6.664 & 21.7 & 0.084 & 20.0 \\
\hline & Model 2 & 5.968 & 10.4 & 0.081 & 3.6 \\
\hline & Model 3 & 3.208 & 46.2 & 0.043 & 46.9 \\
\hline \multirow[t]{4}{*}{ Heart disease } & Model 0 & 10.310 & & 0.102 & \\
\hline & Model 1 & 8.214 & 20.3 & 0.077 & 24.5 \\
\hline & Model 2 & 7.251 & 11.7 & 0.074 & 3.9 \\
\hline & Model 3 & 4.355 & 39.9 & 0.041 & 44.6 \\
\hline \multirow[t]{4}{*}{ Stroke } & Model 0 & 38.806 & & 0.097 & \\
\hline & Model 1 & 26.718 & 31.1 & 0.080 & 17.5 \\
\hline & Model 2 & 26.718 & 0.0 & 0.087 & -8.8 \\
\hline & Model 3 & 15.980 & 40.2 & 0.054 & 37.9 \\
\hline \multirow[t]{4}{*}{ Diabetes } & Model 0 & 14.373 & & 0.150 & \\
\hline & Model 1 & 11.386 & 20.8 & 0.121 & 19.3 \\
\hline & Model 2 & 10.880 & 4.4 & 0.118 & 2.5 \\
\hline & Model 3 & 6.172 & 43.3 & 0.053 & 55.1 \\
\hline \multirow[t]{4}{*}{ Cancer } & Model 0 & 18.385 & & 0.146 & \\
\hline & Model 1 & 12.678 & 31.0 & 0.119 & 18.5 \\
\hline & Model 2 & 11.063 & 12.7 & 0.127 & -6.7 \\
\hline & Model 3 & 2.925 & 73.6 & 0.055 & 56.7 \\
\hline \multirow[t]{4}{*}{ Lung disease } & Model 0 & 15.855 & & 0.111 & \\
\hline & Model 1 & 10.276 & 35.2 & 0.065 & 41.4 \\
\hline & Model 2 & 9.553 & 7.0 & 0.061 & 6.2 \\
\hline & Model 3 & 3.316 & 65.3 & 0.000 & 100.0 \\
\hline \multirow[t]{4}{*}{ Arthritis } & Model 0 & 7.907 & & 0.084 & \\
\hline & Model 1 & 5.965 & 24.6 & 0.059 & 29.8 \\
\hline & Model 2 & 5.495 & 7.9 & 0.056 & 5.1 \\
\hline & Model 3 & 2.575 & 53.1 & 0.025 & 55.4 \\
\hline
\end{tabular}

Model 0: Duration after diagnosis and (duration after diagnosis) ${ }^{2}$

Model 1: Model $0+$ age at diagnosis (centered to 70 years old), gender, education level

Model 2: Model $1+$ number of comorbidities over time

Model 3: Model $2+$ depression status over time

gender, marital status, education, and economic status. Disability has been shown to be more common in females and in divorced/separated/widowed respondents, and has been positively associated with increasing age and inversely associated with education and economic status $[28,29]$. In the current study, subjects who were older at the initial diagnosis, female, who had lower educational levels had higher levels of physical disability for all chronic conditions, which was consistent with the findings of prior studies [28, 29].

Multiple existing studies have shown that multimorbidity is associated with disability after controlling for sociodemographic status $[13,17,30,31]$. In the present study, comorbidity explained small parts of the variance after controlling for sociodemographic covariates. It accounted for $4.4-12.7 \%$ of the changes in the variances in the intercept and $2.5-6.2 \%$ of the changes in the variances in physical disability over time in chronic conditions, with the exception of stroke and cancer. The influences of comorbidity on disability for stroke were inconsistent. In Stenholm's study, comorbidity was associated with a greater burden of physical functioning difficulties, and stroke alone or in combination with other diseases is one of the diseases leading to the most limitations in terms of physical functioning [13]. However, in Lopez-Espuela's study, comorbid conditions did not affect the patients' functional status 6 months after they had experienced a stroke [32], which was similar to our 
results. Further detailed exploration discussing the discrepancies in comorbidity on disability related to stroke is therefore needed.

Depression associated with disability is well-established in prior literature in the general elderly population [27, 33], with one study reporting that depression increases the risk of subsequent ADL disability and mobility disability by 67 and 73\%, respectively [27]. In addition, one study targeting the diabetes population showed disability to be greater in diabetes patients with depressive symptoms [34]. Indeed, there's a wide spectrum of opinions on the mechanism for the causal relationship between disability and depression. Some studies have clearly shown that medical illness and physical disability are strongly associated with depression [35, 36]. And the association between disability and increased prevalence of depression irrespective of physical health problems was tested and result showed all ADL/IADL limitations are significantly associated with depression [36]. On the other hand, one cohort study has shown that depression in initial non-disabled older persons significantly increases the risk for subsequent incident ADL and mobility disability [27]. The explanation for depression leading to disability in that study is that lower levels of physical activity and fewer contacts with relatives among depressed persons. Thus, the causal relationship between disability and depression is bidirectional depending on different clinical situations. In our study, time-varying depression status explained a great amount of the variance after controlling for the aforementioned covariates, with $39.9-73.6 \%$ changes in the variances in the intercept and $37.9-100 \%$ of the changes in the variances in physical disability over time, which was in line with previous findings. The results of this study suggest that depression status may have an impact on physical disability and that intervention for depression management may have a protective effect against the trend in increased physical disability.

This study has some limitations. First, self-reported information on chronic conditions and physical function were used in this national cohort database. The reporting and recall bias from self-reported information may lead to underestimation of disease prevalence, and thus, the results should be interpreted with caution. However, previous studies have shown high levels of accuracy between self-reported data and clinical diagnoses for diseases such as hypertension and diabetes and fair accuracy for lung disease, cardiac disease, stroke, and malignancies, with the exception of arthritis [37-39]. Future research including formal medical records on disease status is encouraged to minimize such biases. Second, the TLSA database does not include annual interviews with the respondents, so we could only record physical disability scores at 3 to 4 year intervals to estimate the trajectories. Thus, subtle between-interval changes in physical disability may have been missed. Also, there may have been a survivorship bias due to the increasing mortality associated with the duration of the disease. Third, because the present study was aimed toward describing development of disability after a diagnosis of different chronic conditions, the time axis was fixed to years after diagnosis. Thus, a comparison of the disability burden related to each chronic condition with the normal aging process could not be achieved via this study. In future studies, researchers are encouraged to use age as a time axis to distinguish the burden of each chronic condition as compared with normal aging [20]. Finally, due to the limited TLSA interview data, we were unable to distinguish participants' economic status and further chronic condition details, such as disease type, severity and self-management status. The current work could only depict the mean physical disability trajectory, so future studies with detailed disease status information may help clarify their contribution to the physical disability trajectory. Also, common mental diseases such as depression and memory-related diseases were not included in our self-reported chronic condition questionnaire, so future studies could include such diseases simultaneously for comparison.

\section{Conclusions}

Despite the fact that a comparison across conditions was not statistically tested, an accelerated increase in physical disabilities was found as chronic conditions progressed. While stroke and cancer lead to disability immediately, conditions such as diabetes, cancer, and hypertension give rise to higher increments of physical disability in later stages of disease. Mitigating depressive symptoms may be beneficial in terms of preventing disability development in this population.

\section{Abbreviations}

ADL: Activities of Daily Living; IADL: Instrumental Activities of Daily Living; TLSA: Taiwan Longitudinal Study on Aging; CES-D: Centers for

Epidemiological Studies-Depression; MLM: Multilevel Modeling; SD: Standard Deviation; Cl: Confidence Interval

\section{Acknowledgements \\ We are grateful to Health Data Science Center, National Cheng Kung University Hospital for providing administrative and technical support.}

\section{Authors' contributions}

CJC took responsibility for the integrity of the data and the accuracy of the analysis and guided the study design, statistics, and discussion. CYC reviewed the literature, analyzed the data, and wrote the manuscript. CMC, $\mathrm{CHW}, \mathrm{FHL}, \mathrm{JSW}$, and YCY contributed to the discussion, suggestion and advice. All authors have read and approved the manuscript.

\section{Funding}

This work was supported by a grant from the Ministry of Science and Technology (PI: Ching-Ju Chiu, MOST 107-2314-B-006-005-MY3). The funders had no role in study design, data collection and analysis, decision to publish, or preparation of the manuscript. 


\section{Availability of data and materials}

The data that support the findings of this study are available from Health Data Science Center, National Cheng Kung University Hospital, but restrictions apply to the availability of these data, which were used under license for the current study and are thus not publicly available. Data are, however, available from the authors upon reasonable request and with permission of the Health Data Science Center, National Cheng Kung University Hospital.

\section{Declarations}

\section{Ethics approval and consent to participate}

The Health Data Science Center at National Cheng Kung University Hospital granted permission to use the raw data. The Ethical Committee for Human Research at National Cheng Kung University Hospital approved this study (BER-104-077) and waived informed consent.

\section{Consent for publication}

Not applicable.

\section{Competing interests}

The authors declare that they have no competing interests.

\section{Author details}

${ }^{1}$ Institute of Gerontology, College of Medicine, National Cheng Kung University, No. 1, University Road, 70101 Tainan, Taiwan. ${ }^{2}$ Department of Family Medicine, National Cheng Kung University Hospital, Tainan, Taiwan. ${ }^{3}$ Department of Medicine, College of Medicine, National Cheng Kung University, Tainan, Taiwan. ${ }^{4}$ Division of Geriatrics and Gerontology, Department of Internal Medicine, National Cheng Kung University Hospital, Tainan, Taiwan. ${ }^{5}$ Department of Family Medicine, College of Medicine, National Cheng Kung University, Tainan, Taiwan.

Received: 19 August 2020 Accepted: 8 March 2021

Published online: 23 March 2021

\section{References}

1. He W, Goodkind D, Kowal P. In: Bureau USC, editor. An aging world: 2015. Washington, DC: U.S. Government Publishing Office; 2016.

2. National Development Council. Population Projections for R.O.C. (Taiwan): 2018-2065. 2018. https://pop-proj.ndc.gov.tw/upload/download/中華民國 人口推估(2018至2065年).pdf.

3. Ministry of Health and Welfare ROC. Report of the Senior Citizen Condition Survey 2013. 2014

4. Kalyani RR, Saudek CD, Brancati FL, Selvin E. Association of diabetes, comorbidities, and A1C with functional disability in older adults: results from the National Health and nutrition examination survey (NHANES), 19992006. Diabetes Care. 2010:33(5):1055-60. https://doi.org/10.2337/dc09-1597.

5. Scuteri A, Spazzafumo L, Cipriani L, Gianni W, Corsonello A, Cravello L, Repetto L, Bustacchini S, Lattanzio F, Sebastiani M. Depression, hypertension, and comorbidity: disentangling their specific effect on disability and cognitive impairment in older subjects. Arch Gerontol Geriatr. 2011;52(3):253-7. https://doi.org/10.1016/j.archger.2010.04.002.

6. Adamson J, Beswick A, Ebrahim S. Is stroke the most common cause of disability? J Stroke Cerebrovasc Dis. 2004;13(4):171-7. https://doi.org/10.101 6/j.jstrokecerebrovasdis.2004.06.003.

7. Bauer UE, Briss PA, Goodman RA, Bowman BA. Prevention of chronic disease in the 21st century: elimination of the leading preventable causes of premature death and disability in the USA. Lancet. 2014;384(9937):45-52. https://doi.org/10.1016/S0140-6736(14)60648-6.

8. Katz S, Akpom CA. A measure of primary sociobiological functions. Int J Health Serv. 1976;6(3):493-508. https://doi.org/10.2190/UURL-2RYU-WRYD-EY3K.

9. Lawton MP, Brody EM. Assessment of older people: self-maintaining and instrumental activities of daily living. Gerontologist. 1969;9(3):179-86. https://doi.org/10.1093/geront/9.3_Part_1.179.

10. Hardy SE, Kang Y, Studenski SA, Degenholtz HB. Ability to walk 1/4 mile predicts subsequent disability, mortality, and health care costs. J Gen Intern Med. 2011;26(2):130-5. https://doi.org/10.1007/s11606-010-1543-2.

11. Lin KC, Chen PC, Twisk JW, Lee HL, Chi LY. Time-varying nature of risk factors for the longitudinal development of disability in older adults with arthritis. J Epidemiol. 2010;20(6):460-7. https://doi.org/10.2188/jea.JE20090154.
12. Yokota RT, Berger N, Nusselder WJ, Robine JM, Tafforeau J, Deboosere P, et al. Contribution of chronic diseases to the disability burden in a population 15 years and older, Belgium, 1997-2008. BMC Public Health. 2015;15(1):229. https://doi.org/10.1186/s12889-015-1574-z.

13. Stenholm S, Westerlund H, Head J, Hyde M, Kawachi I, Pentti J, Kivimäki M, Vahtera J. Comorbidity and functional trajectories from midlife to old age: the health and retirement study. J Gerontol A Biol Sci Med Sci. 2015;70(3): 332-8. https://doi.org/10.1093/gerona/glu113.

14. Chiu CJ, Wray LA. Physical disability trajectories in older Americans with and without diabetes: the role of age, gender, race or ethnicity, and education. Gerontologist. 2011;51(1):51-63. https://doi.org/10.1093/geront/gnq069.

15. Ettinger WH Jr, Fried LP, Harris T, Shemanski L, Schulz R, Robbins J. Selfreported causes of physical disability in older people: the cardiovascular health study. CHS collaborative research group. J Am Geriatr Soc. 1994; 42(10):1035-44. https://doi.org/10.1111/j.1532-5415.1994.tb06206.x.

16. Balzi D, Lauretani F, Barchielli A, Ferrucci L, Bandinelli S, Buiatti E, Milaneschi Y, Guralnik JM. Risk factors for disability in older persons over 3-year followup. Age Ageing. 2010;39(1):92-8. https://doi.org/10.1093/ageing/afp209.

17. Qian J, Ren X. Association between comorbid conditions and BADL/IADL disability in hypertension patients over age 45: based on the China health and retirement longitudinal study (CHARLS). Medicine (Baltimore). 2016; 95(31):e4536. https://doi.org/10.1097/MD.0000000000004536.

18. Wong E, Backholer K, Gearon E, Harding J, Freak-Poli R, Stevenson C, Peeters A. Diabetes and risk of physical disability in adults: a systematic review and meta-analysis. Lancet Diabetes Endocrinol. 2013;1(2):106-14. https://doi. org/10.1016/S2213-8587(13)70046-9.

19. Dhamoon MS, Longstreth WT Jr, Bartz TM, Kaplan RC, Elkind MSV. Disability Trajectories Before and After Stroke and Myocardial Infarction: The Cardiovascular Health Study. JAMA Neurol. 2017;74(12):1439-45.

20. Chiu CJ, Wray LA, Ofstedal MB. Diabetes-related change in physical disability from midlife to older adulthood: evidence from 1996-2003 survey of health and living status of the elderly in Taiwan. Diabetes Res Clin Pract. 2011;91(3): 413-23. https://doi.org/10.1016/j.diabres.2010.12.003.

21. Martinez CH, Richardson CR, Han MK, Cigolle CT. Chronic obstructive pulmonary disease, cognitive impairment, and development of disability: the health and retirement study. Ann Am Thorac Soc. 2014;11(9):1362-70. https://doi.org/10.1513/AnnalsATS.201405-1870C.

22. Nagi SZ. An epidemiology of disability among adults in the United States. Milbank Mem Fund Q Health Soc. 1976;54(4):439-67. https://doi.org/10.23 07/3349677.

23. Radloff LS. The CES-D scale: a self-report depression scale for research in the general population. Appl Psychol Meas. 1977;1(3):385-401.

24. Chang K-F, Weng L-J. Screening for depressive symptoms among older adults in Taiwan: Cutoff of a short form of the Center for Epidemiologic Studies Depression Scale. Health (N Y). 2013;5(03):588.

25. Bryk AS, Raudenbush SW. Application of hierarchical linear-models to assessing change. Psychol Bull. 1987;101(1):147-58. https://doi.org/10.1037/ 0033-2909.101.1.147.

26. Spiers NA, Matthews RJ, Jagger C, Matthews FE, Boult C, Robinson TG, Brayne C. Diseases and impairments as risk factors for onset of disability in the older population in England and Wales: findings from the Medical Research Council cognitive function and ageing study. J Gerontol A Biol Sci Med Sci. 2005;60(2):248-54. https://doi.org/10.1093/gerona/60.2.248.

27. Penninx BW, Leveille S, Ferrucci L, van Eijk JT, Guralnik JM. Exploring the effect of depression on physical disability: longitudinal evidence from the established populations for epidemiologic studies of the elderly. Am J Public Health. 1999;89(9):1346-52. https://doi.org/10.2105/AJPH.89.9.1346.

28. Hosseinpoor AR, Bergen N, Kostanjsek N, Kowal P, Officer A, Chatterji S. Socio-demographic patterns of disability among older adult populations of low-income and middle-income countries: results from world health survey. Int J Public Health. 2016;61(3):337-45. https://doi.org/10.1007/s00038-0150742-3.

29. Balogun SA, Guntupalli AM. Gender difference in the prevalence and sociodemographic correlates of mobility disability among older adults in Nigeria. Eur J Ageing. 2016;13(3):231-9. https://doi.org/10.1007/s10433-016-0386-z.

30. Quinones AR, Markwardt S, Botoseneanu A. Multimorbidity combinations and disability in older adults. J Gerontol A Biol Sci Med Sci. 2016;71(6):82330. https://doi.org/10.1093/gerona/glw035.

31. Su P, Ding H, Zhang W, Duan G, Yang Y, Chen R, Duan Z, du L, Xie C, Jin C, Hu C, Sun Z, Long J, Gong L, Tian W. The association of multimorbidity and disability in a community-based sample of elderly aged 80 or older in 
Shanghai, China. BMC Geriatr. 2016;16(1):178. https://doi.org/10.1186/s12 877-016-0352-9.

32. Lopez-Espuela F, Pedrera-Zamorano JD, Jimenez-Caballero PE, RamirezMoreno JM, Portilla-Cuenca JC, Lavado-Garcia JM, et al. Functional status and disability in patients after acute stroke: a longitudinal study. Am J Crit Care. 2016;25(2):144-51. https://doi.org/10.4037/ajcc2016215.

33. Deschenes SS, Burns RJ, Schmitz N. Associations between depression, chronic physical health conditions, and disability in a community sample: a focus on the persistence of depression. J Affect Disord. 2015;179:6-13. https://doi.org/10.1016/j.jad.2015.03.020.

34. Wu CY, Terhorst L, Karp JF, Skidmore ER, Rodakowski J. Trajectory of disability in older adults with newly diagnosed diabetes: role of elevated depressive symptoms. Diabetes Care. 2018;41(10):2072-8. https://doi.org/1 0.2337/dc18-0007.

35. Weinberger MI, Raue PJ, Meyers BS, Bruce ML. Predictors of new onset depression in medically ill, disabled older adults at 1 year follow-up. Am J Geriatr Psychiatry. 2009;17(9):802-9. https://doi.org/10.1097/JGP.0b013e3181 b0481a.

36. Meltzer H, Bebbington P, Brugha T, McManus S, Rai D, Dennis MS, Jenkins R. Physical ill health, disability, dependence and depression: results from the 2007 national survey of psychiatric morbidity among adults in England. Disabil Health J. 2012;5(2):102-10. https://doi.org/10.1016/j.dhjo.2012.02.001.

37. Wu SC, Li CY, Ke DS. The agreement between self-reporting and clinical diagnosis for selected medical conditions among the elderly in Taiwan. Public Health. 2000;114(2):137-42. https://doi.org/10.1016/50033-3 506(00)00323-1.

38. Kriegsman DM, Penninx BW, van Eijk JT, Boeke AJ, Deeg DJ. Self-reports and general practitioner information on the presence of chronic diseases in community dwelling elderly. A study on the accuracy of patients' selfreports and on determinants of inaccuracy. J Clin Epidemiol. 1996;49(12): 1407-17. https://doi.org/10.1016/S0895-4356(96)00274-0.

39. Robinson JR, Young TK, Roos LL, Gelskey DE. Estimating the burden of disease. Comparing administrative data and self-reports. Med Care. 1997; 35(9):932-4. https://doi.org/10.1097/00005650-199709000-00006.

\section{Publisher's Note}

Springer Nature remains neutral with regard to jurisdictional claims in published maps and institutional affiliations.

\section{Ready to submit your research? Choose BMC and benefit from:}

- fast, convenient online submission

- thorough peer review by experienced researchers in your field

- rapid publication on acceptance

- support for research data, including large and complex data types

- gold Open Access which fosters wider collaboration and increased citations

- maximum visibility for your research: over $100 \mathrm{M}$ website views per year

At BMC, research is always in progress.

Learn more biomedcentral.com/submissions 